\title{
RESUMO
}

\section{A INCLUSÃO NO BRASIL: A DEFICIENCIA INTELECTUAL E AS CONTRIBUIÇ̃̃ES DE VIGOTSKI}

INCLUSION IN BRAZLL: INTELLECTUAL DISABILITY AND VIGOTSKI'S CONTRIBUTIONS

INCLUSIÓN EN BRASIL: DISCAPACIDAD INTELECTUAL Y CONTRIBUCIONES DE VIGOTSKI
0 artigo realiza uma reflexão sobre a inclusão de alunos com deficiência intelectual nas escolas e a contribuição de Vigotski no seu processo de ensino e aprendizagem. Para isso o artigo apresenta alguns momentos histórica sobre a trajetória da pessoa com deficiência no mundo, sua legislação no Brasil e a concepção de Vigotski sobre deficiência. Por fim o artigo propõe um debate sobre as reais possibilidades de se implementar os conceitos do psicólogo russo na educação especial em deficiência intelectual.

\section{PALAVRA-CHAVE}

Educação Especial. Deficiência Intelectual. Inclusão. 


\section{ABSTRACT}

The article reflects on the inclusion of students with intellectual disabilities in schools and Vygotsky's contribution to his teaching and learning process. For this, the article presents some historical moments about the trajectory of people with disabilities in the world, their legislation in Brazil and Vygotsky's conception of disability. Finally, the article proposes a debate about the real possibilities of implementing the concepts of the Russian psychologist in special education in intellectual disabilities.

\section{KEYWORD}

Special Education; Intellectual Disability; Inclusion.

\section{RESUMEN}

El artículo reflexiona sobre la inclusión de estudiantes con discapacidad intelectual en las escuelas y lacontribución de Vigotski a suproceso de enseñanza y aprendizaje. Para esto, el artículo presenta algunos momentos históricos sobre la trayectoria de las personas con discapacidad en el mundo, su legislación en Brasil y la concepción de discapacidad de Vigotski. Finalmente, el artículo propone un debate sobre las posibilidades reales de implementar los conceptos del psicólogo ruso en educación especial en discapacidad intelectual.

\section{PALABRAS CLAVE}

Educación Especial; Discapacidad intelectual; Inclusión. 


\section{INTRODUÇ̃̃O}

Este artigo tem por objetivo discutir a inclusão no Brasil e as contribuições de Vigotski nas reflexões relacionadas ao processo de ensino e aprendizagem do aluno com deficiência.

0 processo de inclusão possibilitou novas discussões sobre as teorias que poderiam aprimorar o processo de aprendizagem desse aluno dentro da escola. Entretanto, esse contexto provocou diferentes desafios sobre as barreiras físicas, atitudinais e culturais enfrentadas por esses alunos, assim como reflexões sobres às práticas conservadoras em relação ao seu processo de ensino e aprendizagem (UNESCO, 1994).

No caso do aluno com deficiência intelectual, esse contexto provocou uma reação contrária em relação a sua inclusão devido ao olhar negativo do passado sobre os seus aspectos cognitivos. A atenção estava centrada no defeito e na limitação e não nas relações entre pessoas e no acesso ao conhecimento (OLIVEIRA, 2002; SMOLKA; LAPLANE, 2005).

Apesar das dificuldades enfrentadas por esses alunos no sistema regular de ensino, inicia-se de forma mais intensa no século XX um processo de construção de políticas públicas, de âmbito internacional, estadual e municipal, relacionadas à educação inclusiva e teorias relacionadas à aprendizagem do aluno com deficiência intelectual, procurando desconstruir esse olhar negativo em relação ao aluno com deficiência.

Com o objetivo de refletir sobre esse contexto o artigo procurou apresentar alguns marcos históricos e legais sobre a deficiência no mundo, no Brasil e a teoria de Vigotski como uma possibilidade de reflexão sobre aprendizagem do aluno com deficiência intelectual.

\section{BREVE APRESENTAÇÃO HISTÓRICA DA DEFICIÊNCIA NO MUNDO}

Este item pretende apresentar, de forma resumida, alguns momentos históricos sobre a deficiência na sociedade ocidental, seguindo uma ordem cronológica dos diferentes momentos vividos pela pessoa com deficiência desde a antiguidade até a atualidade.

$\mathrm{Na}$ antiguidade, nas sociedades ocidentais divididas entre nobreza e servos, organizadas economicamente nas atividades agrícolas, pecuárias e artesanais, o povo não possuía nenhum poder político, vivendo em absoluta exclusão. Nesse cenário, a pessoa diferente, com restrições funcionais e necessidades individualizadas, era praticamente exterminada por meio do abandono, o que não importava um problema de caráter ético ou moral (ARANHA, 2001).

$\mathrm{Na}$ idade média, com aparecimento do cristianismo e o fortalecimento da Igreja Católica. Esse novo contexto modificou a forma de se compreender a deficiência. Todas as pessoas passaram a ser considerados filhos de Deus e possuidores de uma alma. Entretanto, a abordagem em relação ao diferente ainda variava de acordo com o seu grupo, sendo que alguns eram objetos de caridade e outros considerados como resultantes de possessão demoníaca. De qualquer forma, a pessoa com deficiência era insignificante no contexto da organização social (PESSOTTI, 1984; ARANHA, 2001). 
No século XVI com a Revolução Burguesa muda a forma de se compreender o homem e a sociedade. A visão mais abstrata, metafísica do homem transforma-se e torna-se mais concreta. A deficiência passou a ser considerada de natureza médica e vista como produto de infortúnios naturais e atributos do indivíduo. Do ponto de vista econômico eram consideradas improdutivas. Nesse mesmo período, surgiu o primeiro hospital psiquiátrico com o objetivo de retirar do convívio social pessoas com comportamento fora do padrão social (ARANHA,1995; 2001).

No século XVII, com o capitalismo comercial e o fortalecimento da burguesia no poder, a diferença entre os indivíduos passou a ser considerada legitima no sentido de justificar a desigualdade social. Nesse mesmo período surgiram novas ideias relacionadas à medicina, filosofia e educação, porém em relação à deficiência o caráter organicista predominou (PESSOTTI, 1984).

Nessa mesma época surgiu John Locke (1632 - 1741) que lutou contra os absolutismos teocráticos da época, admitindo que, dependendo da qualidade da interação que o deficiente mental mantém, a educação do mesmo era possível.

Para o filósofo a deficiência mental era concebida numa perspectiva naturalista. A partir da teoria da tabula rasa, na qual a mente seria uma página em branco onde a experiência individual daria condições para que as operações mentais se efetuassem, a deficiência mental passa a ser considerado um "estado de carências de ideias e operações intelectuais", cabendo à educação supri-las. Entretanto, o poder público e as famílias não viam vantagens em relação a essa responsabilidade, restando ao deficiente inútil, à lavoura, artesanato e os asilos (PESSOTTI, 1984).

Entre o século os XVIII e XIX privilegiou-se a segregação com a fundação dos institutos cujo objetivo era promover uma educação a parte. Esse mesmo período foi marcado pela assimilação e consolidação do conhecimento produzido pela medicina enquanto a deficiência mental continuava sendo considerada incurável. Alguns tratamentos trouxeram melhoras, entretanto essas pessoas ainda eram abandonadas em hospícios (PESSOTTI, 1984).

No século XIX surgiu o primeiro teórico da Educação Especial, o médico Jean Itard e, o seu primeiro desafio foi promover avanços educacionais em um menino encontrado no sul da França diagnosticado como idiota, sem possibilidade alguma de educação. Itard foi reconhecido por utilizar métodos sistematizados de estimulação e reabilitação para o ensino de deficientes mentais, obtendo avanços significativos que constituíram os fundamentos da avaliação e da didática na deficiência intelectual (PESSOTTI,1984; CARNEIRO, 2007; PLETSCH,2009).

Édouard Séguin, discípulo de Itard, criticou a visão médica de incurabilidade e desenvolveu um método consistia em estimular o cérebro por meio de atividades físicas e sensoriais; seus trabalhos Influenciaram Pestalozzi, Froebel e Montessori cujos estudos estavam direcionados à pessoa com deficiência intelectual. Em 1837, na França, criou a primeira escola para deficientes intelectuais e foi em 1876 a Associação Americana de Retardo Mental [AAMR] conhecida como Associação Americana de Deficiência Intelectual e Desenvolvimento [AAIDD] (MIRANDA, 2003; PLETSCH, 2009).

Segundo Aranha, ainda nesse mesmo século, houve uma atitude pública em relação às necessidades das pessoas com deficiência e um enfoque educacional voltado para suas as potencialidades (ARANHA, 1995). 
No século XX incidiu a aceitação e a integralização da pessoa com deficiência numa visão organicista, médica. Segundo Pessotti (1984) surge à psicologia científica, que tem como foco a mente e em conjunto com a medicina e a pedagogia científica, levantam uma questão: como medir as diferenças de capacidade mental entre normais e débeis mentais? Com os estudos de Alfred Binet (1857 - 1911) a deficiência mental passa a ser estudada pela psicologia e o Quociente Intelectual (QI) o parâmetro para se identificar a pessoa com deficiência intelectual.

Atualmente, no século XXI, apresenta a perspectiva da inclusão e a superação dos novos desafios da pessoa com deficiência nos espaços sociais.

\section{BREVE APRESENTAÇÃO HISTÓRICA E LEGAL SOBRE A DEFICIÊNCIA NO BRASIL}

O atendimento escolar especial teve seu início no Brasil em 1854 por D. Pedro II com a fundação do Imperial Instituto dos Meninos Cegos e o Instituto dos Surdos-Mudos em 1857 ambos na cidade do Rio de Janeiro.

A fundação dos institutos possibilitou uma maior discussão e conscientização sobre questões relacionadas à educação do deficiente. Durante esse período, final do século XIX e início do século XX, duas vertentes marcaram o atendimento ao deficiente: médico-pedagógico e psicopedagógico.

A vertente médico-pedagógico que se caracterizava pela preocupação eugênica e higienizadora da comunidade no Brasil, estimulando a criação de escolas em hospitais constituindo-se em um atendimento mais segregado em relação ao deficiente (JANUZZI, 2004; MENDES,1995; DECHICHI, 2001).

A vertente psicopedagógica defendia a educação dos indivíduos anormais. Seus seguidores utilizavam recursos pedagógicos alternativos e escalas de inteligência para identificar níveis intelectuais das crianças e jovens. Essa vertente prevaleceu sobre a primeira e sua tendência diagnóstica implementou medidas segregadoras, originando as classes especiais para deficientes mentais (JANUZZI, 1992; DECHICHI, 2001).

Na década de 1920, sob os ideários da Escola Nova, professores-psicólogos europeus foram trazidos para o Brasil com o objetivo de oferecer cursos aos professores brasileiros, influenciando os rumos da Educação Especial.

Em 1932, a psicóloga russa Helena Antipoff responsável para criação das classes e escolas especiais, fundou a Sociedade Pestalozzi de Minas Gerais para atender deficientes e participou ativamente da criação da primeira Associação de Pais e Amigos dos Excepcionais (APAE) em 1954; contribuiu para a formação e o aumento de profissionais que foram trabalhar na Educação Especial no país (JANUZZI, 1992; MENDES, 1995).

Entre as décadas de 1930 e 1940 as mudanças na educação brasileira, como a expansão do ensino primário e secundário, foram direcionadas a educação da pessoa normal. A educação da pessoa com deficiência, nesse mesmo período, não era uma preocupação, muito menos um problema a ser resolvido (MENDES,1995; DECHICHI, 2001).

Já na década de 1950 houve uma expansão das classes especiais e escolas especiais públicas, comunitárias, privadas e sem fins lucrativos. Durante essa década, o governo federal começou a 
assumir, por meio de campanhas em nível nacional, o atendimento educacional aos indivíduos com deficiência (MENDES, 1995).

Na década de 1960 ocorreu à maior expansão de escolas de ensino especial para deficientes mentais e uma tímida preocupação com a educação dos excepcionais com a LDB 4024/61 de 20 de dezembro de 1961, que apresentou em seu capítulo III Dos Estabelecimentos Isolado de Ensino Superior, título X Da Educação de Excepcionais.

Na década 1970 ocorreu a institucionalização da Educação Especial com a criação do Centro Nacional de Educação Especial (CENESP) com a finalidade de promover, em todo o território nacional, a melhoria do atendimento aos excepcionais (MAZZOTA, 1996, p. 55).

Em 1971 a Lei de Diretrizes e Bases da Educação Nacional (LDB) n 5.692 promulgada em 11 de agosto, fixou as Diretrizes e Bases para o Ensino de $1^{\circ} \mathrm{e} 2^{\circ} \mathrm{grau}$ que previu o "tratamento especial" aos alunos com deficiência mental. A preocupação em relação à educação dos alunos com deficiência física e mental se traduziu em apenas um artigo e não apresentou nenhuma orientação em relação ao significado do que seria esse tratamento especial. Entretanto, o aspecto positivo em relação à legislação foi atrelar a Educação Especial ao ensino regular.

A década de 1980 representou um período marcado por lutas sociais e avanços conquistados pela população marginalizada. Influenciada pela Declaração Universal dos Direitos da Criança da Organização das Nações Unidas (ONU, 1959), a Constituição Federal de 1988, capítulo III Da Educação, Da Cultura e Do Desporto, seção I Da Educação em seu artigo 208 garantiu à participação do Estado no atendimento educacional especializado e o inciso III no qual define o atendimento educacional especializado aos portadores de deficiência, preferencialmente na rede regular de ensino.

Ao disciplinar o atendimento educacional especializado a Constituição de 1988 fortaleceu o processo de inclusão dos alunos com deficiência na rede regular de ensino, assim como seu atendimento educacional especializado. Entretanto, o atendimento educacional não atingiu o princípio proposto pela Constituição de acesso à escolaridade (MENDES,1995).

A década de 1990 foi marcada por documentos internacionais que colocaram em pauta o tema inclusão e os direitos da pessoa com deficiência no Brasil, dentre eles, a Declaração Mundial de Educação para Todos (UNESCO); a Declaração de Salamanca (ONU) e a Convenção de Guatemala.

Segundo a Declaração de Salamanca (1994) a escola inclusiva é o lugar onde todas as crianças devem aprender juntas, sempre que possível independentemente de quaisquer dificuldades ou diferenças que elas possam ter, conhecendo e respondendo as necessidades diversas de seus alunos, acomodando ambos os estilos e ritmos de aprendizagem, assegurando uma educação de qualidade a todos por meio de um currículo apropriado, arranjos organizacionais, estratégias de ensino, usam de recursos e parcerias com as comunidades.

Sob a influência desses documentos, em 1990 o Estatuto da Criança e do Adolescente (ECA) Lei $n^{\circ} 8092 / 90$, reiterou os princípios defendidos pela Constituição, garantindo os direitos da criança com deficiência em receber 0 atendimento especializado na rede regular.

Em 1996, a Lei de Diretrizes e Bases 9.394/96 reforçou os princípios propostos pela Constituição Federal de 1988 e expressou em seus conteúdos avanços significativos em relação à educação espe-

Interfaces Científicas - Educação • Aracaju • V.9 - N.1 • p. 93-106 • 2020 - Número Temático - Políticas Públicas Educacionais 
cial. Dedicou todo um capítulo a Educação Especial e a sua preocupação em oferecê-la, preferencialmente, na rede regular de ensino e serviço de apoio educacional especializado (BUENO, 1994).

O artigo 58 reiterou o intuito da Constituição Federal de 1988 e do Estatuto da Criança e do Adolescente, ao compreender a educação especial enquanto modalidade de ensino, assumindo o compromisso com a escola inclusiva.

O artigo 59 apresentou um significativo avanço em relação ao desenvolvimento cognitivo do aluno com deficiência intelectual. 0 artigo demonstrou preocupação em relação aos métodos e técnicas no atendimento às necessidades educacionais aos educandos com deficiência, transtornos globais do desenvolvimento e altas habilidades.

Segundo Saviani (2004, não resta dúvida que a educação especial ganha, nesta lei, um lugar mais destacado, ao se configurar um Capítulo autônomo em comparação com a lei 5.692/71 onde o assunto foi regulamentado em apenas um artigo (o art. $9^{\circ}$ ) do Capítulo I que trata das disposições comuns ao ensino de primeiro e segundo grau).

Posteriormente, outros documentos reafirmaram essa mesma preocupação em relação ao desenvolvimento do aluno com deficiência. Em conformidade com a LDB n 9394/96 a Câmara de Educação Básica do Conselho Nacional da Educação (CEB/ CNB), instituiu por meio da Resolução $n^{\circ} 2$ de 11 de setembro de 2001 as Diretrizes Nacionais para a Educação Especial na Educação Básica.

A Resolução definiu a importância da capacitação dos professores comuns e especiais no atendimento dos alunos com necessidades especiais; apresentou a ideia de adaptação curricular e o serviço de apoio especializado nas salas de recursos que complemente e suplemente o currículo.

Seria importante salientar que o conceito de inclusão passou a predominar em relação ao conceito de integralização. Na integralização, a pessoa para ser inserida na escola regular deve apresentar condições para frequentá-la, ou corresponder as suas solicitações. Na inclusão, a inserção da pessoa com deficiência passa pelo reconhecimento da existência das inúmeras diferenças (pessoais, culturais, sociais etc.), ocasionando uma necessidade de mudanças no sistema educacional (BUENO, 1999).

Nesse sentido, documentos oficiais reforçam as mudanças relacionadas à inclusão e a pessoa com deficiência. Em 2002 o Conselho Nacional de Educação por meio da Resolução n 1/2002 institui as Diretrizes Curriculares Nacionais para a Formação de Professores da Educação Básica, em nível superior, curso de licenciatura e graduação plena, sua preocupação em discutir, nos cursos de formação de professores, conhecimentos relacionados aos alunos com necessidades educacionais especiais.

Com o objetivo de difundir a cultura de direitos humanos no país, o Plano Nacional de Educação em Direitos Humanos instituído em 2006 estabeleceu em seus objetivos sua preocupação em incentivar formas de acesso às ações de educação em direitos humanos a pessoas com deficiência.

Em 2007 o Decreto n⿳0 6.094/07 delineou o Plano de Metas Compromisso Todos pela Educação. Ficou estabelecida em suas diretrizes a garantia do acesso e permanência das pessoas com necessidades educacionais especiais nas classes comuns do ensino regular, fortalecendo a inclusão educacional nas escolas públicas.

0 Decreto $n^{\circ} 7.611 / 11$ no qual dispõe sobre a educação especial, o atendimento educacional especializado, ampliou a oferta do atendimento educacional especializado aos estudantes 
com deficiência, transtorno global do desenvolvimento e altas habilidades ou superdotação, matriculados na rede pública de ensino regular.

O Plano Nacional de Educação (PNE), aprovado pela Lei 13.005/14 garantiu novos avanços em relação à educação especial. 0 objetivo do Plano foi estabelecer diretrizes, metas e estratégias, visando atender as determinações definidas pelo artigo 214 da Constituição Federal de 1988.

Com o objetivo de universalizar o atendimento escolar, o Plano Nacional de Educação, definiu a diretriz para a Educação Especial. Segundo o Plano ficou estabelecido que os Estados, o Distrito Federal e os Municípios ao elaborarem os seus planos, deverão em consonância com PNE, definir políticas de ensino que garantam o atendimento das necessidades específicas na educação especial, assegurado o sistema educacional inclusivo em todos os níveis, etapas e modalidades (BRASIL, 2014).

Diante das metas e estratégia estabelecidas pelo PNE se verificou avanços legais no tratamento da pessoa com deficiência. Em 2015 a Lei Brasileira de Inclusão da Pessoa com Deficiência n¹3.146/15 reforçou a garantia da educação escolar para a pessoa com deficiência. Segundo a lei, a recusa do aluno com deficiência nos estabelecimentos de ensino constitui crime com punição de 2 a 5 anos de reclusão.

Os documentos oficiais evidenciaram a trajetória da deficiência no Brasil e tiveram como meta organizar o sistema de ensino com a finalidade de atender o público alvo da educação especial na escola regular, assim como o atendimento educacional especializado. Esse novo contexto legal e teórico permitiu uma maior reflexão sobre a teoria de Vigotski relacionada à educação do deficiente, superando o modelo puramente biológico.

\section{A DEFICIÊNCIA E VIGOTSKI}

Diante dessa nova compreensão em relação à educação do aluno com deficiência, Lev Semyonovitch Vigotski desde o início século XX desenvolveu estudos em relação à aprendizagem da criança com deficiência.

Segundo Vigotski (1997), a deficiência é muito mais afetada por órgãos sociais do que biológicos; para isso procurou classificar as deficiências em primária, de causa orgânica e secundária, de consequência social da primária. Assim, para Vigotski (1997), as possibilidades de desenvolvimento da criança com deficiência, de modo geral, devem transcender a deficiência a sua condição biológica, consequentemente a sua deficiência secundária.

Em seu livro, Fundamentos da Defectologia, o autor discutiu assuntos acerca do ensino e das características da pessoa com deficiência, buscando a compreensão qualitativa sobre o "funcionamento" do pensamento, suas interações e como enfrentam suas dificuldades (VIGOTSKI, 1997).

A tese central da defectologia é que todo o defeito desenvolve estímulos para elaborar compensação. A criança com deficiência apresenta tendências psicológicas de orientação opostas a deficiência o que possibilita, por meio de vias compensatórias, o desenvolvimento das funções psicológicas superiores (VIGOTSKI, 1997).

Nesse sentido, a educação deve basear-se no fato de que simultaneamente com o defeito estão dadas também as tendências psicológicas de uma direção oposta; estão dadas as possibilidades de 
compensação para vencer o defeito e de que precisamente essas possibilidades se apresentam em primeiro plano como sua força motriz (VIGOTSKI, 1997, p. 32).

Do mesmo modo, o trabalho educativo deverá caminhar no sentido oposto ao da deficiência, ou seja, nas tendências psicológicas nas quais estão dadas as possibilidades de compensação social.

Esse deslocamento do biológico para o social trouxe para a educação uma nova concepção sobre o trabalho educativo em relação à criança com deficiência. A educação dentro dessa perspectiva histórico-cultural obriga a refletir sobre a importância do conhecimento científico e a abstração no processo de inserção da pessoa com deficiência na vida laboral e nas diferentes atividades do seu cotidiano.

Desse modo, para que essa educação histórico-cultural se realize será preciso pensar em um trabalho educativo que valorize o conhecimento científico e a abstração.

Precisamente porque a criança retardada depende tanto de sua experiência de impressões concretas e se desenvolvido tão pouco, em seu próprio pensamento, abstrato, a escola deve liberá-la do método excesso visual-direta, que serve como uma barreira para o desenvolvimento do pensamento abstrato, e educar esses processos. Em outro modo, a escola deve não só adaptar-se às insuficiências da criança, mas também combatê-las, superá-las. (VIGOTSKI, 1997, p. 36).

A criança com deficiência intelectual muito pouco poderá desenvolver seus pensamentos abstratos por conta própria. A escola e seus professores representam para esse aluno o nascimento do conhecimento científico mediante a instrução. É preciso que esta instância promova o acesso dessa criança aos conteúdos historicamente produzidos e sistematizados pela humanidade, podendo empregar para tanto, estratégias de ensino diferenciadas de maneira a propiciar a formação do pensamento abstrato (BERTOLIN, 2015).

A autora acrescenta que para isso ocorrer é importante a atuação efetiva e participativa da figura do professor de maneira a proporcionar "ações educativas que culminem em desenvolvimento e novas aprendizagens no campo da simbolização e pensamento abstrato” (BERTOLIN, 2015, on-line).

Segundo Vigotski, por muito tempo prevaleceu a ideia de que conceitos científicos eram inacessíveis ao sujeito com deficiência intelectual. Este modo de pensar conduziu a um trabalho educativo direcionado apenas para o concreto. Por esse motivo a escolarização da pessoa com deficiência intelectual mental deveria recusar propostas de ensino baseadas na repetição, cópias, experiências concretas, mas sim investir no pensamento abstrato (VIGOTSKI, 1997).

Caberia ao professor, portanto, promover modos de organização e objetivos para a criança com deficiência, visando boas oportunidades de aprendizagem, pois essas são mais importantes que a própria condição orgânica da deficiência. (VIGOTSKI, 1997). Ademais, é importante que ele escolha alternativas de trabalho e aplique-as, do mesmo modo, que "observe a devolutiva que o estudante lhe dá frente às situações de aprendizagem e reavalie o trabalho constantemente de forma a redirecioná-lo quando necessário e prosseguir com práticas assertivas focando em resultados qualitativos" (BERTOLIN, 2015, on-line).

Para que essas oportunidades de aprendizagem ocorram, será preciso considerar o nível de desenvolvimento atual e a zona de desenvolvimento proximal em que a criança se encontra. Esse cuidado 
favorece o modo de como o trabalho educativo será organizado no sentido de promover a instrução eficaz. Essa tese nos propõe uma nova fórmula, a de que o bom aprendizado é somente aquele que se adianta ao desenvolvimento (VIGOTSKI, 2010).

A mediação desse trabalho pela linguagem adquire a função central no processo de aprendizagem do aluno com deficiência intelectual, assim como no processo de formação do pensamento humano. "A linguagem não só cumpre a função de comunicação entre as crianças, mas também é um instrumento do pensamento” (VIGOTISKI, 1997).

A linguagem requer o desenvolvimento de distintas funções psicológicas superiores como a percepção, as operações sensório-motoras, a memória, a atenção, entre outras, as quais fazem parte do processo dinâmico do comportamento (BERTOLIN, 2015).

Cabe explicitar que a mediação, conforme expressa Bertolini (2015), tem papel imprescindível no desenvolvimento do ser humano, porquanto por meio de signos e dos instrumentos que foram construídos o homem se humaniza, se aprimora, se desenvolve, aprende indo além de sua condição biológica.

Vigotski (1997) menciona o afeto como uma alternativa no desenvolvimento da criança com deficiência intelectual. Para ele o afeto-intelecto é compreendido como um movimento em constante transformação de novas tendências psicológicas, novos modos de pensamento e de novas condutas/ ações. 0 argumento construído foi: o afeto é orientado/movido pelo sentido produzido na relação, gerando possibilidades outras de (inter)ação (VIGOTSKI, 1997).

\section{CONCLUSÕES}

Diante desse novo contexto sobre a deficiência, a discussão apresentada neste artigo visou uma maior discussão sobre a possibilidade de se considerar a teoria Vigotski no trabalho docente do professor regular e do professor especializado em educação especial - deficiência intelectual.

A história nos revelou o percurso de exclusão vivido pela pessoa com deficiência nos diferentes momentos históricos. No início do século XX o artigo revelou a mudança de enfoque em relação a pessoa com deficiência, do biológico para histórico-cultural. Esse novo enfoque permitiu um olhar na pessoa com deficiência e não na deficiência. O que é inovador. Esse novo contexto permitiu uma revolução no ambiente escolar, no trabalho pedagógico do professor, na comunidade escolar e no projeto político pedagógico da escola.

Entretanto, não podemos ocorrer em um otimismo pedagógico, acreditando que esse novo olhar em relação à deficiência resolverá as mazelas da educação especial. A escola e seus professores ainda enfrentam muitos problemas relacionados com número de alunos em sala de aula; formação para atender alunos com deficiência; estrutura física; materiais didáticos; o cumprimento das leis; baixos salários; enfim o caminho a ser percorrido ainda é muito longo, porém os primeiros passos foram dados.

Enfim, será preciso uma maior reflexão sobre essa nova demanda na qual a escola não poderá se ausentar. 


\section{REFERÊNCIAS}

ARANHA, M. S. F. Paradigmas da relação da sociedade com as pessoas com deficiência. Revista do Ministério Público do Trabalho, Ano XI, n. 21, p. 160-173, março 2001.

ARANTES, D. R. B.; NAMO, D.; MACHADO, M. P. S. Contexto histórico e educacional da pessoa com deficiência no Brasil e no Estado de São Paulo. In: ALMEIDA, M. A. Deficiência intelectual: realidade e ação. São Paulo, Secretaria da Educação. Núcleo de Apoio pedagógico Especializado: SE, 2012. p.15-33.

ARANTES, D. R. B.; NAMO, D. Deficiência intelectual: da família a escola. Deficiência intelectual: realidade e ação. São Paulo, Secretaria da Educação. Núcleo de Apoio pedagógico Especializado: SE, 2012. p.133-144.

BERTOLIN, F. N. O papel da mediação frente ao estudante com deficiência intelectual: desafios e possibilidades. Seminário Internacional sobre profissionalização docente, 5, 26 a 29 de outubro de 2015. Anais..., Cátedra Unesco. 2015. Disponível em: http://educere.bruc.com.br/arquivo/ pdf2015/17442_8520.pdf. Acesso em: 20 abr. 2017.

BRASIL. Lei no.9394, de 20 de dezembro de 1996. Estabelece as Diretrizes e Bases da Educação Nacional. Diário oficial da União. Brasília, 23 dez.1996.

BRASIL. Constituição (1988). Constituição da República Federativa do Brasil. Brasília, DF: Senado Federal, 1988.

BUENO, J. G. S. Educação especial brasileira: integração/segregação do aluno diferente. São Paulo: Edu, 1993.

BUENO, J. G. S. A inclusão de alunos deficientes nas salas comuns do ensino regular. Temas sobre a desenvolvimento. São Paulo: Memnon. 2001.

LURIA, A. R. 0 desenvolvimento da escrita na criança. In: VIGOTSKI L. S.; LEONTIEV, A. N. Linguagem, desenvolvimento e aprendizagem. 10. ed. São Paulo: Ícone, 2006. p. 143-189.

MADER, D. Integração da pessoa portadora da deficiência: a vivência de um novo paradigma. In: MANTOAN, M. T. E. A integração das pessoas com deficiências. São Paulo:Memnon,1997. p. 44-50

MANTOAN, M. T. E. Inclusão escolar para deficientes mentais: que formação para o professor? In: MANTOAN, M. T. E. A integração de pessoas com deficiência. São Paulo: Memnon, 1997b. p. 119-27. 
MARTINS, M. H.; ALMEIDA, A. S.; JESUS, S.N. Da educação especial a escola inclusiva. In: STOUBAUS, C. D.; MOSQUERA, J. J. M. Educação especial: em direção a uma escola inclusiva. 2. ed. Porto Alegre: Edipucrs, 2004. p. 27-40.

OLIVEIRA, E.; MACHADO, K.S. Adaptação curriculares: caminho para uma educação inclusiva. In: GLAT, R. Educação inclusiva: cultura e cotidiano escolar. Rio de Janeiro:7Letras, 2007. p.36-52.

PALMA FILHO, J. C. A formação do professor na legislação educacional brasileira: avanços e retrocessos. Caderno de formação: módulo introdutório, Pedagogia Cidadã, São Paulo, p. 2-8, 2002.

SÃO PAULO. Secretaria da Educação. Aula de Trabalho Pedagógico Coletivo em Destaque. São Paulo: SE, 2014,

SÃO PAULO. Resolução SE 61, de 11 de novembro de 2014. Dispõe sobre a Educação Especial nas unidades escolares da rede estadual de ensino. São Paulo, 2014.

SAVIANI, D. Pedagogia histórico-crítica: primeiras aproximações. 9. ed. Campinas, SP: Autores Associados, 2005. (Coleção educação contemporânea).

UNESCO - Organização das Nações Unidas para Educação, Ciência e Cultura. Declaração de Salamanca sobre princípios, políticas e práticas em educação especial. Salamanca (Espanha), junho de 1994. Disponível em: http://portal.mec.gov.br/seesp/arquivos/pdf/salamanca.pdf. Acesso em: $15 / 01 / 2020$

VIGOTSKI, L. S. Fundamentos da defectologia. Madrid: Visor, 1997. p.9-12; 36; 99. Obras Escogidas V.

VIGOTSKI, L. S. A construção do pensamento e da linguagem. São Paulo: Martins Fontes, 2001. 
1 Doutor em Educação Escolar pela Faculdade de Ciência e Letras, Universidade Estadual Paulista Júlio de Mesquita Filho - FCLar/UNESP, linha de pesquisa formação de professor e Educação Especial; Mestre em Educação Escolar - FCLar/ UNESP, linha de pesquisa Formação do professor, Trabalho docente e Práticas pedagógicas; Graduado em Pedagogia - FCLar/UNESP, com Habilitação em Deficiência Intelectual; Professor efetivo na rede pública estadual de São Paulo nos cargos, ensino fundamental I desde 2007 e sala de recursos em deficiência intelectual desde 2011; Tem experiência em estudos e pesquisas na área da Educação sobre os seguintes temas: Adaptação Curricular; Deficiência Intelectual; Educação Especial; Formação de Professores; Práticas Pedagógicas. E-mail: arturc@professor.educacao.sp.gov.br

2 Doutora em Educação pela Universidade Federal de São Carlos (1997); Mestra em Fundamentos da Educação pela Universidade Federal de São Carlos (1992); Professora Livre Docente em Sociologia da Educação da Universidade Estadual Paulista Júlio de Mesquita Filho, Departamento de Didática e do Programa de Pós-Graduação em Educação Escolar, na Linha de Pesquisa "Sexualidade, Cultura e Educação Sexual"; Integrante do Núcleo de Estudos da Sexualidade - NUSEX; Tem experiência na área de Educação, trabalhando com a abordagem de Pierre Bourdieu, com ênfase em pesquisas sobre habitus, gênero e trajetórias escolares. E-mail: luci.muzzeti@unesp.br

3 Doutor em Educação Escolar pela Faculdade de Ciências e Letras de Araraquara; Pós-Doutor em Ciências Sociais UNESP/Marília; Professor do Programa de Pós-Graduação em Políticas Públicas da Universidade de Mogi das Cruzes - UMC e do Programa em Gestão e Desenvolvimento Regional pelo Centro Universitário do Sul de Minas - UNIS. E-mail:r.silva@unesp.br
Recebido em: 16 de Janeiro de 2020

Avaliado em: 22 de Fevereiro de 2020

Aceito em: 4 de Março de 2020

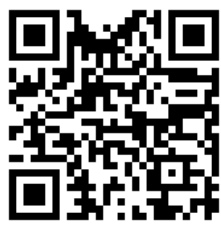

A autenticidade desse artigo pode ser conferida no site https://periodicos. set.edu.br

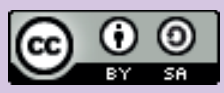

Este artigo é licenciado na modalidade acesso abertosob a Atribuição-Compartilha Igual CC BY-SA

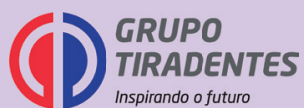

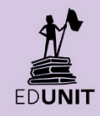


